\title{
A patient with COVID-19 and a skin rash
}

Borja Díaz-Guimaraens, Miguel DomínguezSantás, Diego Fernández-Nieto, Juan JiménezCauhé, Ana Suárez-Valle

\section{CASE}

A woman aged 52 years presented to the emergency department in Madrid, Spain, in December 2020 during the COVID-19 pandemic. She complained of a slightly pruritic rash that had started to appear 10 days earlier (Figures 1 and 2). The lesions developed five days after the onset of an episode of fever, cough and malaise, and the patient was diagnosed with a mild case of COVID-19 due to a positive real-time reverse transcription-polymerase chain reaction for SARS-CoV-2 that had been taken from a nasopharyngeal swab. She had been referred to a dermatologist by her general practitioner (GP), who had suspected COVID-19-associated livedo reticularis and had prescribed acetylsalicylic acid $100 \mathrm{mg}$ once daily. Laboratory tests were unremarkable, apart from a mildly elevated C-reactive protein level (13 mg/L, reference range $<6 \mathrm{mg} / \mathrm{L})$. Proximal and distal arterial pulses were present.

\section{QUESTION 1}

How would you describe the lesions?
QUESTION 2

What history specific to the clinical appearance would you take?

\section{ANSWER 1}

The lesions consisted of dusky hyperpigmented reticulated patches, with superimposed pink keratotic plaques on the inner thighs and legs. No ulceration was present.

ANSWER 2

A history of chronic heat exposure should be sought.

\section{CASE CONTINUED}

The patient acknowledged that, during the previous three months, she had been using a hot water bottle, held between her thighs, to warm herself while in bed.

Although not required for the diagnosis, two 4-mm punch biopsies were taken from one of the reticulated patches on the patient's left thigh and the unaffected area between the patches to evaluate the integrity of the arterial skin supply due to her COVID-19 diagnosis and to rule out vasculitis or vasculopathy.

The biopsy from the reticulated patch showed epidermal atrophy, whereas the other was unspecific. Neither biopsy indicated vasculitis or thrombotic vasculopathy. She was prescribed a betamethasone dipropionate cream $0.05 \%$ twice a day for 14 days and was advised to avoid heat sources. Only a slight hyperpigmented network persisted two months later.

\section{QUESTION 3}

What is the diagnosis?

\section{QUESTION 4}

What differential diagnoses should be considered?

\section{ANSWER 3}

This condition is known as erythema ab igne (EAI), which is a disorder caused by local chronic exposure to low levels of infrared heat below the threshold for a thermal burn (eg after contact with heating pads, hot water bottles, laptop computers). ${ }^{1}$ Clinically, it begins as areas of localised reversible reticulated erythema that reflect the areas of venous predominance in the skin, identical to livedo reticularis, and evolves into a fixed reticulated hyperpigmentation in the same pattern. It is characteristically asymptomatic, although a slight burning sensation can be noted. Biopsy is not needed for the diagnosis. If performed, epidermal atrophy and dermal melanophages are often observed. Management consists of the cessation of 
the offending heat source. It is advised to ask about prior localised pain, as the use of heat might be a sign of suboptimal pain management. It is important to monitor patients who present with EAI and report long-term exposure to heat, as prolonged heat exposure can predispose to the future development of cutaneous squamous cell carcinoma or Merkel cell carcinoma. ${ }^{2}$

\section{ANSWER 4}

It is important to rule out other reticular disorders, such as livedo reticularis, which is a temperature-sensitive vasculopathy that favours the extremities. ${ }^{3}$ The reticulate pattern usually has a red-blue or violaceus hue, and hyperpigmentation is not frequent (which helps to distinguish it from EAI). It can be localised or widespread. It can be physiological (typically widespread and transient, more marked in neonates and infants), primary (persistent, due to a continuous vasospasm of arterioles when secondary aetiologies are ruled out) or secondary. Secondary livedo reticularis can be caused by a vasospasm, as in autoimmune connective tissue diseases or within Raynaud's phenomenon; by vessel wall pathology (inflammation that occludes

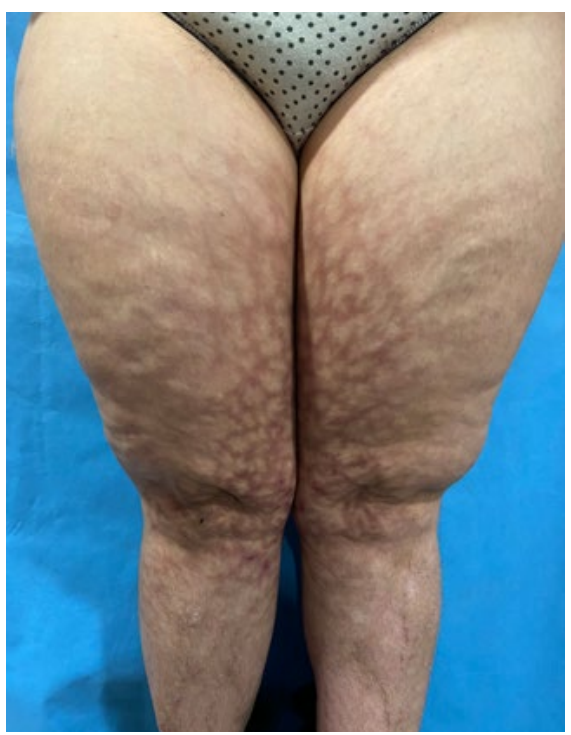

Figure 1. Reticulated erythematous and hyperpigmented patches on both inner thighs and legs the dermal or subcutaneous vessels), as in vasculitis (polyarteritis nodosa, cryoglobulaemic vasculitis), calciphylaxis or livedoid vasculopathy; or because of intraluminal pathology (thrombi), as in antiphospholipid syndrome or due to cholesterol emboli. Secondary livedo reticularis is often localised and is usually painful, not pruritic. When suspected, a comprehensive review of other organs and systems must be performed. It has been described in association with severe COVID-19 cases, and it is believed to be caused by microthrombi that occlude the smallest cutaneous vessels or because of complement-mediated inflammation. ${ }^{4}$

\section{Key points}

- EAI consists of areas of reticulated localised erythema and/or hyperpigmentation.

- It is caused by chronic exposure to heat that does not meet the threshold for a thermal burn.

- It is important to differentiate it from other reticulated dermatoses, such as livedo reticularis.

First published 3 May 2021.

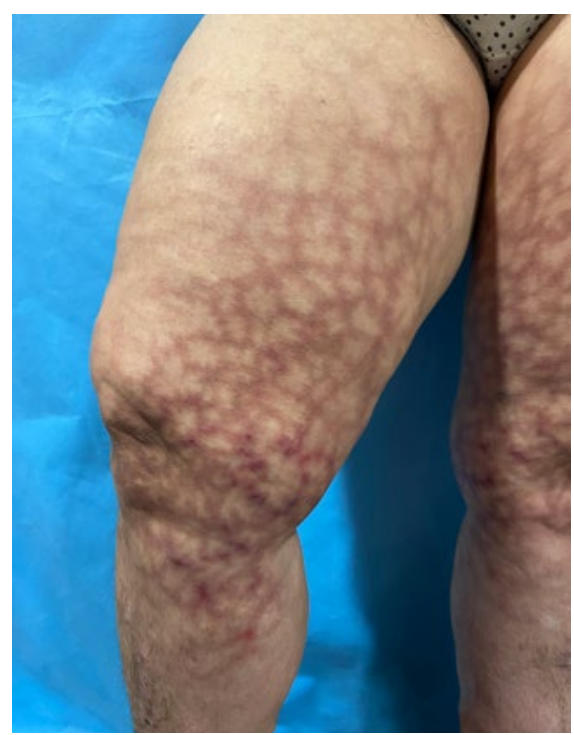

Figure 2. On the inner right leg, reticulated linear erythematous plaques were present

\section{Authors}

Borja Díaz-Guimaraens MD, Dermatologist, Dermatology Department, Hospital Universitario Ramón y Cajal, Madrid, ES

Miguel Domínguez-Santás MD, Dermatologist, Dermatology Department, Hospital Universitario Ramón y Cajal, Madrid, ES

Diego Fernández-Nieto MD, Dermatologist, Dermatology Department, Hospital Universitario Ramón y Cajal, Madrid, ES

Juan Jiménez-Cauhé MD, Dermatologist,

Dermatology Department, Hospital Universitario Ramón y Cajal, Madrid, ES

Ana Suárez-Valle MD, Dermatologist, Dermatology Department, Hospital Universitario Ramón y Cajal, Madrid, ES

Competing interests: None.

Funding: None.

Provenance and peer review: Not commissioned, externally peer reviewed.

Citation: Díaz-Guimaraens B, Domínguez-Santás $\mathrm{M}$, Fernández-Nieto D, Jiménez-Cauhé J, SuárezValle A. A patient with COVID-19 and a skin rash. Aust J Gen Pract 2021;50 Suppl 48. doi: 10.31128/ AJGP-COVID-48.

Correspondence to:

borjadiazguima@gmail.com

\section{References}

1. Tan S, Bertucci V. Erythema ab igne: An old condition new again. CMAJ 2000;162(1):77-78.

2. Arrington JH 3rd, Lockman DS. Thermal keratoses and squamous cell carcinoma in situ associated with erythema ab igne. Arch Dermatol 1979:115(10):1226-28.

3. Sajjan VV, Lunge S, Swamy MB, Pandit AM. Livedo reticularis: A review of the literature. Indian Dermatol Online J 2015;6(5):315-21. doi: 10.4103/2229-5178.164493.

4. Manalo IF, Smith MK, Cheeley J, Jacobs R. A dermatologic manifestation of COVID-19: Transient livedo reticularis. J Am Acad Dermatol 2020;83(2):700. doi: 10.1016/j.jaad.2020.04.018. 